\title{
Validação de fotografias de alimentos para estimativa do consumo alimentar
}

\author{
Validation of food's photographs for \\ estimating the consumption food
}

Rávila Graziany Machado de SOUZA

Marta Isabel Valente Augusto Moraes CAMPOS'

Mariana de Morais CORDEIRO'

Estelamaris Tronco MONEGO'

Maria do Rosário Gondim PEIXOTO'

\section{R E S U M O}

\section{Objetivo}

Validar fotografias de um guia fotográfico de alimentos para estimativa do consumo alimentar.

\section{Métodos}

As fotografias de 12 alimentos (bolo simples, macarrão ao sugo, mamão formosa, melancia, repolho roxo ralado, quiabo refogado, churrasco em tiras, filé de frango grelhado, pudim de leite condensado, pizza, amendoim cru e queijo tipo minas), retratadas em três tamanhos de porções (pequena, média e grande), foram avaliadas por 90 indivíduos adultos. Foram também investigados o peso, a estatura e o sexo dos participantes. Para análise de concordância entre o tamanho da porção do alimento retratado nas fotos e o tamanho real do alimento, utilizou-se o teste Kappa. Os dados foram analisados no software Stata, considerando-se $p<0,05$.

\section{Resultados}

A maior prevalência de acerto foi para as preparações pizza (87,8\%), churrasco $(80,0 \%)$, filé de frango e pudim $(75,5 \%)$. Já os alimentos com menor percentual de acertos foram a melancia $(52,2 \%)$, o mamão formosa e o bolo $(57,8 \%)$. A concordância geral entre a percepção do tamanho da porção do alimento e o tamanho real do alimento foi de $0,622(p<0,001)$. A percepção não foi influenciada pelo sexo e pelo estado nutricional dos participantes $(p>0,05)$.

\section{Conclusão}

As 12 fotografias apresentaram uma boa concordância com as porções dos alimentos e podem ser um instrumento útil para aumentar a acurácia dos relatos do consumo alimentar.

Palavras-chave: Fotografia. Guias alimentares. Ingestão de alimentos. Percepção de tamanho. Tamanho da porção.

\footnotetext{
1 Universidade Federal de Goiás, Faculdade de Nutrição, Programa de Pós-Graduação em Nutrição e Saúde. R. 227, Qd. 68, s/n., Setor Leste Universitário, 74605-080, Goiânia, GO, Brasil. Correspondência para/Correspondence to: RGM SOUZA. E-mail: <ravilagraziany@gmail.com>.
} 


\section{A B S T R A C T}

\section{Objective}

Validate photographs of a photographic guide of foods to estimate food consumption.

\section{Methods}

The photos of 12 foods (simple cake, pasta to suck, papaya, watermelon, grated purple cabbage, okra stew, barbecue into strips, grilled chicken, condensed milk pudding, pizza, raw peanuts and cheese type mines), pictured in three portion sizes (small, medium and large), were evaluated for 90 adult subjects. The weight, height and gender of the participants also were investigated. For analysis of agreement between the size of the food portion pictured in the photos and the actual size of the food used the Kappa test. Data were analyzed using Stata software, considering $p<0.05$.

\section{Results}

The highest prevalence was hit for pizza preparations (87.8\%), barbecue (80.0\%) chicken fillet and pudding (75.5\%), while foods with a lower percentage of correct answers were watermelon (52.2\%), the papaya and cake (57.8\%). The overall agreement between the perception of the size of the food portion and the actual size of the food was $0.622(p<0.001)$. The perception was not influenced by sex and nutritional status of participants $(p>0,05)$.

\section{Conclusion}

We conclude that the 12 photographs showed a good agreement with the portions of food and can be a useful instrument to increase the accuracy of dietary intake reports.

Keywords: Photography. Food guide. Food intake. Size perception. Portion size.

\section{N T R O D U Ç Ã O}

Associações entre as escolhas alimentares e a ocorrência de doenças têm sido feitas desde a antiguidade, o que evidencia uma estreita relação entre a dieta e o estado de saúde do indivíduo. Por essa razão, a verificação do padrão de consumo de alimentos é oportuna tanto para o diagnóstico quanto para as recomendações nutricionais ${ }^{1,2}$.

Avaliações quantitativas da dieta requerem determinação precisa do volume de alimentos consumidos, no entanto, conhecer a ingestão alimentar exata de grupos ou mesmo de indivíduos é sempre uma tarefa complexa. A diversidade de alimentos, a variedade de utensílios, a padronização inadequada de medidas caseiras, o viés de memória do entrevistado, a falta de treinamento do entrevistador e o próprio instrumento de inquérito dietético utilizado são algumas das possíveis limitações encontradas na quantificação do consumo alimentar ${ }^{3,4}$.

O uso de recursos visuais para avaliação da ingestão alimentar é uma estratégia utilizada em pesquisas e na prática clínica, com utilização de álbuns de fotografias, modelos tridimensionais de alimentos ou de medidas caseira ${ }^{5}$. As fotografias têm merecido destaque graças ao baixo custo, à longa vida útil, facilidade de transporte e à possibilidade de representar uma ou mais porções de um mesmo alimento ${ }^{6}$.

Na elaboração de um guia fotográfico, detalhes como o tamanho da imagem, a variedade de tamanhos de porções, o intervalo das gramaturas entre elas, os tipos de alimentos, o ângulo da fotografia, a iluminação e outros itens da técnica fotográfica podem exercer influência positiva ou negativa sobre os resultados obtidos ${ }^{7,8}$. A escolha do método utilizado para a validação pode influenciar os resultados, sendo dois tipos usados: a validação por memória -, que é a capacidade de um indivíduo em relembrar a quantidade de alimento consumida e relacioná-la com a foto de uma determinada porção -, e a validação por percepção, método escolhido neste trabalho, que é a capacidade do indivíduo em associar o alimento real a uma foto 9 .

Por essa razão, os guias fotográficos de porções de alimentos constituem ajuda bidimen- 
sional amplamente utilizada, uma vez que apresentam diferentes modelos e tamanhos de utensílios e de alimentos que facilitam no seu reconhecimento quanto às porções habituais da dieta do entrevistado ${ }^{6}$. Percebe-se, no Brasil, a escassez de instrumentos que permitam a visualização de porções de alimentos, e pouco se sabe sobre a percepção dos usuários quanto às fotografias que compõem esses instrumentos. A utilização de um recurso visual atualizado e uma boa percepção dos usuários das imagens apresentadas podem auxiliar na determinação mais precisa do consumo alimentar ${ }^{10-12}$. Diante dessa necessidade, este estudo teve como objetivo validar as fotografias de um guia fotográfico de alimentos para estimativa do consumo alimentar.

\section{MÉ T O D OS}

O estudo foi realizado no ano de 2013. Para a seleção dos alimentos, listaram-se aqueles incluídos em estudos de abrangência nacional, como o Guia Alimentar para a População Brasileira $^{13}$ e o Estudo Multicêntrico sobre Consumo Alimentar ${ }^{14}$. A partir dessa lista de alimentos, foram definidos como critérios de inclusão alimentos de difícil estimativa do consumo alimentar; e como critério de exclusão alimentos cujas medidas caseiras fossem facilmente reconhecidas por meio de utensílios, como os alimentos líquidos, assim como os industrializados e fáceis de quantificar, como balas, snacks, barras de cereais, biscoitos, embutidos. Do total de 157 alimentos, 49 foram apresentados em porções individuais nos tamanhos pequeno, médio e grande, totalizando 147 porções de alimentos. Para a avaliação da percepção das fotografias, foram selecionados 12 alimentos: bolo simples, macarrão ao sugo, mamão formosa, melancia, repolho roxo ralado, quiabo refogado, churrasco em tiras, filé de frango grelhado, pudim de leite condensado, pizza, amendoim cru e queijo tipo minas, totalizando 48 porções de alimentos avaliados (24,5\% de representatividade).
Para cada alimento ou preparação, foram definidos três tamanhos de porções, sendo a porção média aquela referida por Philppi ${ }^{15}$ e pelo Ministério da Saúde ${ }^{16}$. A partir da porção média foram calculados os tamanhos das porções pequena e grande, sendo a primeira obtida pela subtração de $50 \%$ do total da gramatura da porção média e a segunda por meio da soma de $50 \%$, representando a meia porção e a porção e meia respectivamente. Para fins deste estudo, as porções foram denominadas de tamanho pequeno, médio e grande.

Todas as porções de alimentos foram preparadas no Laboratório de Dietética da Faculdade de Nutrição (FANUT) da Universidade Federal de Goiás (UFG), sendo submetidas à aferição de peso em balança marca Filizola ${ }^{\circledR}$, com capacidade máxima de $3 \mathrm{~kg}$ e precisão de 0,5 g. Para alimentos como pizza, pastel, torta de frango e coxinha, não porcionados no Guia Alimentar, foi feita a ordenação crescente de 30 resultados de pesagem do mesmo tipo de alimento oferecido em dez pontos de venda, incluindo feiras, supermercados, bares, lanchonetes, confeitarias e estabelecimentos comerciais, escolhidos por conveniência em bairros distintos da cidade de Goiânia (GO) na tentativa de identificar as variações existentes nesses alimentos. A porção média foi definida pela medida de localização central da distribuição dos dados (mediana), determinada pela média aritmética dos dois elementos centrais.

A série fotográfica foi realizada em estúdio junto ao Laboratório de Dietética para garantir que não houvesse perda das características sensoriais do alimento após seu preparo. Optou-se por um fundo de cor neutra (cinza) e pela presença de talheres (faca e garfo), a fim de que os indivíduos pudessem reconhecer o tamanho das porções representadas nas imagens da série fotográfica por meio da comparação com algo que Ihes remetesse ao seu cotidiano. Todas as porções foram acondicionadas em prato de porcelana branco raso, deixando apenas a porção do alimento em evidência. Para cada tamanho de porção foi realizada uma foto, obtendo-se, assim, 
três fotos de cada alimento ou preparação. As fotografias foram produzidas por profissional habilitado, por meio de câmera fotográfica Canon ${ }^{\circledR} 40$ D com lente Canon 70-200 mm, utilizando-se o mesmo ângulo da lente fotográfica em relação ao alimento $\left(45^{\circ}\right)$ e reveladas no tamanho 10/15 (cm), na forma colorida (Figura 1).

Para a obtenção dos alimentos in natura, como frutas, vegetais e castanhas, e dos alimentos minimamente processados, como o queijo e os doces, procedeu-se a uma seleção a fim de se garantirem os melhores alimentos em relação à cor, à textura e ao tamanho médio da porção. Com relação às preparações de alimentos, foram utilizadas fichas técnicas de preparação testadas e padronizadas pela equipe.

\section{Percepção das fotografias}

Foi realizado um estudo piloto com 30 voluntários e utilizados como critérios de inclusão: ser servidor, acadêmico ou prestador de serviços gerais da Faculdade de Enfermagem da UFG, com idade igual ou superior a 18 anos e capacidade de ler e escrever, para melhor compreensão do método de percepção das fotografias, e como critérios de exclusão: ser estudante de nutrição ou nutricionista. Os participantes eram convidados a sentar-se em uma mesa, na qual havia uma preparação de determinado alimento e três fotografias do mesmo alimento, sendo cada uma representativa de um dos tamanhos de porções do referido alimento. O voluntário deveria avaliar o alimento e marcar no questionário a opção de



Figura 1. Layout de algumas fotografias representando as porções pequenas, médias e grandes. 
qual fotografia era representativa daquela porção de alimento. No estudo piloto, foram avaliados 12 diferentes tipos de alimentos. Durante o estudo piloto, observou-se a importância de se separar cada participante com divisórias nas mesas, a fim de garantir a concentração dos participantes e também delimitar o tempo de avaliação. Após as adequações relatadas, foi realizado o estudo da avaliação da percepção, o qual teve a participação de 90 voluntários, selecionados seguindo os mesmos critérios de inclusão e exclusão do estudo piloto. Todos os avaliadores tiveram seu peso e estatura coletados a fim de se calcular o Índice de Massa Corporal (IMC), que foi analisado conforme proposto por World Health Organization ${ }^{17}$. Para a coleta do peso, utilizou-se uma balança digital com capacidade de até $150 \mathrm{~kg}$ e precisão de $100 \mathrm{~g}$ da marca Plenna ${ }^{\circledR}$, e para a medida da altura, foi utilizado um estadiômetro vertical fixo à parede com variação de $0,1 \mathrm{~cm}$ da marca Sanny ${ }^{\circledR}$. Os dados antropométricos coletados foram necessários para verificar se o estado nutricional avaliado pelo IMC teria influência na escolha do tamanho da porção e na percepção da fotografia.

Para a etapa da avaliação da percepção, foram utilizadas as mesmas preparações do estudo piloto: dois cereais (bolo simples e macarrão ao sugo), duas frutas (mamão formosa e melancia), dois vegetais (repolho roxo ralado e quiabo refogado), duas carnes (churrasco em tiras e filé de frango grelhado), uma preparação doce (pudim de leite condensado), uma preparação salgada (pizza), uma oleaginosa (amendoim cru) e um alimento derivado do leite (queijo tipo minas), portanto foram avaliados 36 fotografias pelos 90 voluntários do estudo. Esse número foi definido considerando que uma amostra entre 50 e 100 pessoas é suficiente para validação de instrumentos para avaliação do consumo alimentar e de outras escalas empregadas na área da saúde.

Diante da dificuldade de se avaliarem todos os alimentos e preparações (147 porções), foram selecionados os alimentos que, na visão dos pesquisadores, poderiam causar dúvidas sobre a percepção da avaliação das fotografias. Também se teve o cuidado de colocar pelo menos um alimento de cada grupo alimentar. Todos os alimentos foram submetidos ao pré-preparo e/ou preparo com a utilização de fichas técnicas padronizadas e porcionadas de acordo com a gramatura e medida caseira previamente estabelecidas para cada tamanho de porção.

Todos os voluntários avaliaram as 12 preparações definidas de forma que, a cada avaliador, foi apresentado apenas um dos três tamanhos da porção do alimento real a ser avaliado, e foi solicitado que ele identificasse o tamanho correspondente a partir de um conjunto contendo três fotografias de tamanho $10 \times 15 \mathrm{~cm}$ (porção pequena, média e grande). Os participantes dispunham de um tempo mínimo de 30 segundos para avaliar o alimento apresentado e sua correspondência, em termos quantitativos, de uma das três fotografias apresentadas. O tamanho real da porção testada era conhecido apenas pelos pesquisadores, os quais utilizaram três tipos de sequências pré-estabelecidas e codificadas em um gabarito. Dessa forma, cada fotografia foi identificada com uma das seguintes letras ( $T, U, C$ ), escolhida ao acaso e que não apresentava nenhum significado relativo no estudo. Cada respondente foi instruído a assinalar no formulário a letra que, em sua opinião, mais se assemelhasse quantitativamente à porção apresentada ${ }^{18}$.

Os dados coletados foram digitados no software Epi Info versão 3.3.2 e as análises estatísticas foram realizadas utilizando o software Stata versão 12.0. Os acertos e erros na estimativa das porções foram apresentados em frequências absolutas e relativas. Foi feito o teste do Qui-quadrado para amostras únicas para avaliar a associação entre estado nutricional e sexo e a estimativa do tamanho da porção, considerando-se significante um $p<0,05$. Para análise de concordância entre o tamanho real do alimento e a percepção do tamanho da porção, foi utilizado o teste Kappa e sua interpretação ocorreu considerando valores de Kappa $<0,20$ (concordância fraca), $\geq 0,20$ a $<0,40$ (concordância regular), 
$\geq 0,40$ a $<0,60$ (concordância moderada), $\geq 0,60$ a $<0,80$ (concordância boa) e $\geq 0,80$ (concordância quase perfeita) ${ }^{19}$. Este estudo foi aprovado pelo Comitê de Ética em Pesquisa da UFG (Protocolo $n^{\circ} 47 / 2008$ ). Todos os participantes assinaram o Termo de Consentimento Livre e Esclarecido.

\section{RES U LT A DOS}

O guia fotográfico resultou em 157 alimentos e preparações, dos quais 108 foram fotografados de forma a apresentar as variedades, como os tipos de bananas (nanica, prata, maçã, ourinho, terra), e 49 alimentos foram apresentados em porções individuais nos tamanhos pequeno, médio e grande, totalizando 147 porções de alimentos. Os alimentos selecionados para validação da percepção, bem como sua gramatura, encontram-se descritos na Tabela 1.

Os voluntários, em sua maioria $(n=77$; $85,56 \%$ ), eram do sexo feminino, com a média de $25 \pm 10,3$ anos. Em relação ao estado nutricional dos participantes, a maior parte $(n=66$; $73,3 \%$ ) foi classificada como eutróficos e $26,7 \%$ com excesso de peso. Não foi encontrada associação entre a estimativa do tamanho das porções dos alimentos com o sexo e o estado nutri- cional dos participantes ( $p \geq 0,05$ para todas as fotografias avaliadas).

Considerando todos os tamanhos de porções, observou-se que os alimentos/preparações cujas porções tiveram maior percentual de acertos foram a pizza $(n=79 ; 87,7 \%)$, seguida do churrasco $(n=72 ; 80,0 \%)$, filé de frango e pudim ( $n=68 ; 75,5 \%)$. Enquanto o alimento com menor percentual de acerto foi a melancia $(n=47$; $52,2 \%$ ), seguida pelo amendoim cru, bolo simples e mamão formosa, estes com $57,8 \%(n=52)$ de acerto. A concordância entre a percepção do tamanho da porção do alimento e o tamanho real do alimento, medida pelo teste Kappa, foi quase perfeita para a pizza $(p<0,001)$, concordância boa para o churrasco, filé de frango, pudim e quiabo $(p<0,001)$, moderada para repolho, macarrão, bolo, mamão, amendoim e melancia $(p<0,001)$, e regular para a melancia $(p<0,001)$. O Kappa combinado considerando todos os alimentos foi de 0,622 ( $p<0,001)$ (Tabela 1).

Quando avaliada a percepção da porção pequena dos alimentos (Tabela 2), constatou-se que a maioria dos alimentos apresentou mais de $70 \%$ de acerto, sendo que amendoim cru, churrasco, mamão formosa e pizza apresentaram 90\% ou mais de acerto. O pior desempenho foi para a melancia, com $20 \%$ de acerto e $80 \%$ de superestimava no tamanho da porção.

Tabela 1. Gramatura das porções pequena, média e grande, frequências de acertos e erros na avaliação da percepção das fotografias e concordância entre a percepção dos avaliadores e o real tamanho das porções dos alimentos/preparações.

\begin{tabular}{|c|c|c|c|c|c|c|c|c|}
\hline \multirow{2}{*}{ Alimentos/preparações } & \multicolumn{3}{|c|}{ Quantidade das porções (g) } & \multicolumn{2}{|c|}{ Total de acertos } & \multicolumn{2}{|c|}{ Total de erros } & \multirow{2}{*}{ Карра* } \\
\hline & Pequena & Média & Grande & $\mathrm{n}$ & $\%$ & $\mathrm{n}$ & $\%$ & \\
\hline Pizza & 50 & 100 & 150 & 79 & 87,8 & 11 & 12,2 & 0,83 \\
\hline Churrasco & 46 & 92 & 138 & 72 & 80,0 & 18 & 20,0 & 0,72 \\
\hline Filé de frango & 50 & 100 & 150 & 68 & 75,5 & 22 & 24,4 & 0,65 \\
\hline Pudim & 45 & 90 & 135 & 68 & 75,5 & 22 & 24,4 & 0,65 \\
\hline Quiabo refogado & 26 & 52 & 78 & 66 & 73,3 & 24 & 26,6 & 0,62 \\
\hline Queijo minas & 20 & 40 & 60 & 62 & 68,9 & 28 & 31,1 & 0,57 \\
\hline Repolho roxo & 36 & 72 & 108 & 60 & 66,6 & 30 & 33,3 & 0,52 \\
\hline Macarrão ao sugo & 53 & 105 & 158 & 60 & 66,6 & 30 & 33,3 & 0,52 \\
\hline Bolo simples & 25 & 50 & 75 & 52 & 57,8 & 38 & 42,2 & 0,40 \\
\hline Mamão formosa & 80 & 160 & 240 & 52 & 57,8 & 38 & 42,2 & 0,40 \\
\hline Amendoim cru & 10 & 20 & 30 & 52 & 57,8 & 38 & 42,2 & 0,40 \\
\hline Melancia & 148 & 296 & 444 & 47 & 52,2 & 43 & 47,8 & 0,30 \\
\hline
\end{tabular}

Nota: *Todos os valores de Kappa com $p<0,001$ 
Na avaliação da porção média (Tabela 3), bolo simples, churrasco, filé de frango, macarrão ao sugo, pizza e quiabo refogado apresentaram mais de $70,0 \%$ de acerto. O erro no reconhecimento da fotografia da porção média do amendoim desviou-se igualmente para a fotografia da porção pequena e grande (50,0\%). Melancia e repolho roxo apresentaram o pior desempenho (43,3\% de acerto). Para a melancia, dos 56,6\% dos indivíduos que erraram, todos superestimaram para a porção grande. E para o repolho roxo, dos $56,6 \%$ que erraram, a maioria $(94,1 \%)$ também superestimou para uma porção maior.
Para a porção grande dos alimentos, observou-se que a maioria obteve mais de 70,0\% de acertos, sendo que melancia, pizza e repolho roxo tiveram $90,0 \%$ ou mais de acerto. Já o amendoim cru $(86,6 \%)$, bolo simples $(73,3 \%)$ e mamão formosa $(76,6 \%)$ tiveram o maior percentual de erro e, consequentemente, de subestimativa do seu tamanho. O percentual de acerto da porção grande do bolo simples foi baixa $(26,6 \%)$, e $100,0 \%(n=22)$ dos participantes que erraram a classificaram como sendo a porção média. De forma semelhante, a fotografia representativa da porção grande do macarrão ao sugo apresentou um percentual de acertos inferior a 60,0\% (Tabela 4).

Tabela 2. Frequências de acertos e erros na avaliação da percepção das fotografias de porções pequenas e desvios dos erros.

\begin{tabular}{|c|c|c|c|c|c|c|c|c|}
\hline \multirow{3}{*}{$\begin{array}{l}\text { Fotografias dos alimentos/ } \\
\text { preparações pequenas }\end{array}$} & \multicolumn{4}{|c|}{ Estimativa das porções pequenas } & \multirow{2}{*}{\multicolumn{2}{|c|}{$\begin{array}{l}\text { Desvio para } \\
\text { porção média }\end{array}$}} & \multirow{2}{*}{\multicolumn{2}{|c|}{$\begin{array}{l}\text { Desvio para } \\
\text { porção grande }\end{array}$}} \\
\hline & \multicolumn{2}{|c|}{ Acerto } & \multicolumn{2}{|c|}{ Erro } & & & & \\
\hline & $\mathrm{n}$ & $\%$ & $\mathrm{n}$ & $\%$ & $\mathrm{n}$ & $\%$ & $\mathrm{n}$ & $\%$ \\
\hline Melancia & 6 & 20,0 & 24 & 80,0 & 21 & 87,5 & 3 & 12,5 \\
\hline Macarrão ao sugo & 19 & 63,3 & 11 & 36,6 & 10 & 90,9 & 1 & 9,1 \\
\hline Repolho roxo & 20 & 66,6 & 30 & 33,3 & 8 & 80,0 & 2 & 20,0 \\
\hline Quiabo refogado & 20 & 66,6 & 10 & 33,3 & 9 & 90,0 & 1 & 10,0 \\
\hline Bolo simples & 21 & 70,0 & 9 & 30,0 & 6 & 66,6 & 3 & 33,3 \\
\hline Filé de frango & 22 & 73,3 & 8 & 26,6 & 7 & 87,5 & 1 & 12,5 \\
\hline Queijo minas & 23 & 76,6 & 7 & 23,3 & 6 & 85,7 & 1 & 14,3 \\
\hline Pudim & 26 & 86,6 & 4 & 13,3 & 2 & 50,0 & 2 & 50,0 \\
\hline Pizza & 27 & 90,0 & 3 & 10,0 & 2 & 66,6 & 1 & 33,3 \\
\hline Churrasco & 27 & 90,0 & 3 & 10,0 & 2 & 66,6 & 1 & 33,3 \\
\hline Amendoim cru & 28 & 93,3 & 2 & 6,6 & 0 & 0,0 & 2 & 100,0 \\
\hline Mamão formosa & 29 & 96,6 & 1 & 3,3 & 1 & 100,0 & 0 & 0,0 \\
\hline
\end{tabular}

Tabela 3. Frequências observadas para acertos e erros na avaliação da percepção das fotografias de porções médias e desvios dos erros.

\begin{tabular}{|c|c|c|c|c|c|c|c|c|}
\hline \multirow{3}{*}{$\begin{array}{l}\text { Fotografias dos alimentos/ } \\
\text { preparações médias }\end{array}$} & \multicolumn{4}{|c|}{ Estimativa das porções médias } & \multirow{2}{*}{\multicolumn{2}{|c|}{$\begin{array}{c}\text { Desvio para } \\
\text { porção pequena }\end{array}$}} & \multirow{2}{*}{\multicolumn{2}{|c|}{$\begin{array}{c}\text { Desvio para } \\
\text { porção grande }\end{array}$}} \\
\hline & \multicolumn{2}{|c|}{ Acerto } & \multicolumn{2}{|c|}{ Erro } & & & & \\
\hline & $n$ & $\%$ & $n$ & $\%$ & $n$ & $\%$ & $\mathrm{n}$ & $\%$ \\
\hline Melancia & 13 & 43,3 & 17 & 56,6 & 0 & 0,0 & 17 & 100,0 \\
\hline Repolho roxo & 13 & 43,3 & 17 & 56,6 & 1 & 5,8 & 16 & 94,1 \\
\hline Mamão formosa & 16 & 53,3 & 14 & 46,6 & 11 & 78,5 & 3 & 21,4 \\
\hline Amendoim cru & 20 & 66,6 & 10 & 33,3 & 5 & 50,0 & 5 & 50,0 \\
\hline Pudim & 20 & 66,6 & 10 & 33,3 & 3 & 30,0 & 7 & 70,0 \\
\hline Queijo minas & 20 & 66,6 & 10 & 33,3 & 7 & 70,0 & 3 & 30,0 \\
\hline Churrasco & 22 & 73,3 & 8 & 26,6 & 2 & 25,0 & 6 & 75,0 \\
\hline Filé de frango & 22 & 73,3 & 8 & 26,6 & 0 & 0,0 & 8 & 100,0 \\
\hline Pizza & 23 & 76,6 & 7 & 23,3 & 1 & 14,3 & 6 & 85,7 \\
\hline Quiabo refogado & 23 & 76,6 & 7 & 23,3 & 1 & 14,3 & 6 & 85,7 \\
\hline Bolo simples & 23 & 76,6 & 7 & 23,3 & 3 & 42,8 & 4 & 57,1 \\
\hline Macarrão ao sugo & 24 & 80,0 & 6 & 20,0 & 1 & 16,6 & 5 & 83,3 \\
\hline
\end{tabular}


Tabela 4. Frequências observadas para acertos e erros na avaliação da percepção das fotografias de porções grandes e desvios dos erros.

\begin{tabular}{|c|c|c|c|c|c|c|c|c|}
\hline \multirow{3}{*}{$\begin{array}{l}\text { Fotografias dos alimentos/ } \\
\text { preparações grandes }\end{array}$} & \multicolumn{4}{|c|}{ Estimativa das porções grandes } & \multirow{2}{*}{\multicolumn{2}{|c|}{$\begin{array}{c}\text { Desvio para } \\
\text { porção pequena }\end{array}$}} & \multirow{2}{*}{\multicolumn{2}{|c|}{$\begin{array}{c}\text { Desvio para } \\
\text { porção média }\end{array}$}} \\
\hline & \multicolumn{2}{|c|}{ Acerto } & \multicolumn{2}{|c|}{ Erro } & & & & \\
\hline & $n$ & $\%$ & $n$ & $\%$ & $\mathrm{n}$ & $\%$ & $\mathrm{n}$ & $\%$ \\
\hline Amendoim cru & 4 & 13,3 & 26 & 86,6 & 1 & 3,8 & 25 & 96,1 \\
\hline Mamão formosa & 7 & 23,3 & 23 & 76,6 & 7 & 30,4 & 16 & 69,5 \\
\hline Bolo simples & 8 & 26,6 & 22 & 73,3 & 0 & 0,0 & 22 & 100,0 \\
\hline Macarrão ao sugo & 17 & 56,6 & 13 & 43,3 & 3 & 23,0 & 10 & 76,9 \\
\hline Queijo minas & 19 & 63,3 & 11 & 36,6 & 1 & 9,1 & 10 & 90,9 \\
\hline Pudim & 22 & 73,3 & 8 & 26,6 & 0 & 0,0 & 8 & 100,0 \\
\hline Churrasco & 23 & 73,3 & 7 & 23,3 & 1 & 14,3 & 6 & 85,7 \\
\hline Quiabo refogado & 23 & 76,6 & 7 & 23,3 & 1 & 14,3 & 6 & 85,7 \\
\hline Filé de frango & 24 & 80,0 & 6 & 20,0 & 0 & 0,0 & 6 & 100,0 \\
\hline Repolho roxo & 27 & 90,0 & 3 & 10,0 & 1 & 33,3 & 2 & 66,6 \\
\hline Melancia & 28 & 93,3 & 2 & 6,6 & 1 & 50,0 & 1 & 50,0 \\
\hline Pizza & 29 & 96,6 & 1 & 3,3 & 0 & 0,0 & 1 & 100,0 \\
\hline
\end{tabular}

A pizza foi um dos alimentos com maior percentual de acertos em todos os tamanhos de porções. Em relação ao amendoim, verificou-se que a maior porcentagem de acertos ocorreu com as fotos das porções pequenas $(93,3 \%)$, reduzindo-se a quantidade de acertos progressivamente para as fotografias das porções média $(66,6 \%)$ e grande $(13,3 \%)$ (Tabelas 2,3 e 4).

\section{I S C U S S Ã O}

A validação da percepção dos indivíduos em relação às fotografias do guia elaborado para a avaliação do consumo alimentar demonstra que tal instrumento possui boa concordância entre a percepção do tamanho da porção do alimento e o tamanho real do alimento ${ }^{19}$. A alta porcentagem de acertos encontrada neste estudo, para a maioria das 12 preparações selecionadas, pode ser produto da meticulosidade com que os alimentos foram tratados durante cada etapa de produção das fotografias, incluindo os cálculos para obtenção das gramaturas das porções, a seleção dos alimentos no momento da compra, o intervalo entre o preparo dos alimentos e o momento da realização das fotos, a montagem do cenário com equipamentos profissionais adequados, o controle e a combinação de luz e som- bra e a padronização do ângulo e da lente durante a série fotográfica.

Estudos anteriores observaram que o método de avaliação do consumo por fotografias é válido para estimar o tamanho das porções quando comparado a outros métodos (pesagem real dos alimentos e estimativa visual direta) ${ }^{20,21}$. Williamson et al.20,21 demonstraram que a estimativa dos tamanhos das porções pelas fotos teve correlação positiva com as medidas obtidas pela pesagem do alimento, o que sugere que o método de fotografia digital é uma alternativa validada para medir o tamanho das porções.

O alto percentual de acertos nas porções de pizza pode ser justificado pelo formato geométrico definido (triangular) sem alteração de espessura entre os três tamanhos, o que, provavelmente, favoreceu a estimativa correta da equivalência entre o alimento exposto e a respectiva fotografia. Os resultados apresentados para as porções da melancia e mamão formosa sugerem que os indivíduos consideraram a espessura mais do que a dimensão do alimento como um todo. Assim, foi observado maior percentual de erro no tamanho da porção grande do mamão, que foi subestimado, e da porção pequena de melancia, que foi superestimada. Uma hipótese para isso é a de que as frutas consumidas fatiadas, co- 
mo mamão, melancia, abacaxi e melão, podem aumentar a dificuldade da percepção do tamanho das porções, uma vez que a gramatura será influenciada tanto pela espessura quanto pela profundidade. Novos estudos devem ser desenvolvidos para avaliar como essas variáveis podem influenciar a percepção do tamanho das porções de alimentos porcionados em fatias.

Um dos fatores que podem ter interferido no resultado da percepção da estimativa das porções do bolo e do macarrão foi a pequena diferença visual entre as porções médias e grandes. Observa-se que alimentos que alcançaram o maior percentual de acertos (churrasco, pizza e pudim, respectivamente) fazem parte dos grupos de carnes, gorduras e açúcares, alimentos mais consumidos pela população brasileira22, o que indica possibilidade de haver relação entre a estimativa e o consumo de alimentos, ou seja, seria mais fácil estimar as porções dos alimentos que fazem parte do hábito alimentar.

A forma mais comum de apresentação das fotografias em registros fotográficos é da menor porção para a maior em todas as séries fotográficas. Nesses casos em que as três fotografias de três tamanhos de porções são apresentadas, os sujeitos tendem a escolher a imagem central ${ }^{7}$. Em nosso estudo, apesar de as fotografias terem sido apresentadas de forma aleatória, observou-se uma tendência de os indivíduos escolherem as fotografias das porções de tamanho médio. O guia com imagens de alimentos pode contribuir para minimizar o viés de memória e melhorar a qualidade da informação sobre o tamanho das porções referidas, sendo um instrumento de grande valia na prática do profissional nutricionista $^{10,23}$

É importante ressaltar que são escassos estudos atuais nesse mesmo perfil metodológico. Assim, é fundamental a publicação de mais trabalhos para fundamentar ainda mais os métodos de validação de guias fotográficos bem como seu uso efetivo para estimativa do consumo alimentar. Sugere-se também que os próximos guias elabo- rados apresentem a validação de um maior número de fotografias, sendo esse um fator limitante no estudo.

\section{O N C L U S Ã O}

O percentual de acertos confirma a percepção correta das porções avaliadas por meio das imagens e sugere esse instrumento como ferramenta de representação dos alimentos ingeridos no cotidiano. A estimativa do tamanho das porções não foi influenciada pelo sexo e pelo índice de massa corporal dos indivíduos.

O guia de alimentos é um instrumento útil tanto para inquéritos dietéticos e avaliação de consumo alimentar dos indivíduos quanto para a promoção de hábitos alimentares saudáveis por meio da educação alimentar e nutricional e da demonstração dos respectivos tamanhos de porções dos grupos alimentares.

\section{A GRADECIMENTOS}

A Itamar Sandoval pela produção fotográfica e à Faculdade de Nutrição da Universidade Federal de Goiás.

\section{REFERÊ NCIAS}

1. Neumann AICP, Shirassu MM, Fisberg RM. Consumo de alimentos de risco e proteção para doenças cardiovasculares entre funcionários públicos. Rev Nutr. 2006; 19(1):19-28. http://dx.doi.org/10.1590/ S1415-52732006000100002

2. Popkin BM, Adair LS, Ng SW. Global nutrition transition and the pandemic of obesity in developing countries. Nutr Rev. 2012; 70(1):3-21. http://dx.doi.org/10. 1111/j.1753-4887.2011.00456.

3. Garcia RWD. Representações sobre consumo alimentar e suas implicações em inquéritos alimentares: estudo qualitativo em sujeitos submetidos à prescrição dietética. Rev Nutr. 2004; 17(1):15-28. http://dx.doi.org/10.1590/S1415-52732004000 100002

4. Fisberg RM, Marchioni DML, Colucci ACA. Avaliação do consumo alimentar e da ingestão de 
nutrientes na prática clínica. Arq Bras Endocrinol Metab. 2009; 53(5):617-24. http://dx.doi.org/10. 1590/S0004-27302009000500014

5. Lillegarard IT, Overby NC, Andersen LF. Can children and adolescents use photographs of food to estimate portion sizes? Eur J Clin Nutr. 2005; 59:611-7. http://dx.doi.org/10.1038/1602119

6. Rodrigues AGM, Proença RPC. Uso de imagens de alimentos na avaliação do consumo alimentar. Rev Nutr. 2011; 24(5):765-76. http://dx.doi.org/10. 1590/S1415-52732011000500009

7. Nelson M, Haraldsdóttir J. Food photographs: pratical guidelines II. Development and use of photographic atlases for assessing food portion size. Public Health Nutr. 1998; 1(4):231-7. http:// dx.doi.org/10.1079/PHN19980039

8. Lopez LB, Lonogo EN, Carballido MP, Carlo P. Validación del uso de modelos fotográficos para cuantificar el tamaño de las porciones de alimentos. Rev Chil Nutr. 2006; 33(3):32-41. http://dx.doi.org/ 10.4067/S0717-75182006000500004

9. Guiomar S, Rodrigues T, Cruz C, Vilela S, Lopes C, Torres D. Pilot study in the view of a Pan-European Dietary Survey: Adolescents, adults and the elderly (Paneu) fase piloto do Inquérito Alimentar Europeu (EU-Menu). Instituto Nacional de Saúde Doutor Ricardo Jorge. 2010 [cited 2016 Jan 10]. Available from: http://www.portaldasaude.pt/NR/rdonlyres/ ED84E3B6-30DD-4E92-9E89-BED56BD82A74/0/ boletim_observacoes_2_2012.pdf

10. Monteiro JK, Pfrimer K, Tremeschin MH, Molina MC, Chiarello P, Vanucchi H. Consumo alimentar: visualizando porções. Rio de Janeiro: Guanabara Koogan; 2005.

11. Lopes RPS, Botelho RBA. Álbum fotográfico de porções alimentares. São Paulo: Metha; 2008.

12. Monego ET, Peixoto MRG, Santiago RAC, Gil MF, Cordeiro MM, Campos MIVAM, et al. Alimentos brasileiros e suas porções: um guia para avaliação do consumo alimentar. Rio de Janeiro: Rubio; 2013.

13. Brasil. Ministério da Saúde. Secretaria de Atenção à Saúde. Guia Alimentar para a população brasileira: promovendo a alimentação saudável. Brasília: Ministério da Saúde; 2006 [acesso 2016 jan 19]. Disponível em: http://dtr2004.saude.gov.br/ nutricao/documentos/guia_alimentar_conteudo. pdf

14. Brasil. Ministério da Saúde. Estudo multicêntrico sobre consumo alimentar. Brasília: Ministério da Saúde; 1997.

15. Philippi ST. Nutrição e técnica dietética. São Paulo: Manole; 2003.

16. Brasil. Ministério da Saúde. Agência Nacional de Vigilância Sanitária. Resolução RDC n³59, de 23 de dezembro de 2003. Regulamento técnico de porções de alimentos embalados para fins de rotulagem nutricional. Brasília: Poder Executivo; 2003.

17. World Health Organization. Physical status: The use and interpretation of antropometry. Technical Report Series, nº 854. Geneva; WHO; 1995.

18. Lopez RPS. Percepção para estimativa de porções alimentares: elaboração e avaliação de procedimentos para registro fotográfico [mestrado]. Brasília: Universidade de Brasília; 2007.

19. Landis JR, Koch GG. The measurement of observer agreement for categorical data. Biometrics. 1977; 33(1):159-74.

20. Williamson DA, Allen HR, Martin PD, Alfonso AJ, Gerald B, Hunt A. Comparison of digital photography to weighed and visual estimation of portion sizes. J Am Diet Assoc. 2003; 103(9):1139-45. http:// dx.doi.org/10.1016/S0002-8223(03)00974-X

21. Williamson DA, Allen HR, Martin PD, Alfonso AJ, Gerald B, Hunt A. Digital photography: A new method for estimating food intake in cafeteria settings. Eat Weight Disord. 2004; 9(1):24-8. http:// dx.doi.org/10.1007/BF03325041

22. Instituto Brasileiro de Geografia e Estatística. Pesquisa de orçamentos familiares. Rio de Janeiro; IBGE; 2009.

23. Foster E, Matthews JNS, Nelson M, Harris JM, Mathers JC, Adamson AJ. Accuracy of estimates of food portion size using food photographs: The importance of using age-appropriate tools. Public Health Nutr. 2006; 9(4):504-9. http://dx.doi.org/ 10.1079/phn2005872

Recebido: outubro 2, 2014 Versão final: fevereiro 5, 2016 Aprovado: fevereiro 17, 2016 